Macedonian Pharmaceutical Bulletin, 66 (Suppl 1) 25 - 26 (2020)

Online ISSN $1857-8969$

UDC: 633.888-28:615.918]:543.544.068.7

DOI: 10.33320/maced.pharm.bull.2020.66.03.012

Short communication

\title{
Analysis of ergosterol as a potential contaminant in two herbal raw materials
}

\author{
Kristina Varsamovska ${ }^{1}$, Zoran Zhivikj $^{2}$, Marina Topkoska ${ }^{1}$, \\ Tatjana Kadifkova Panovska ${ }^{2}$, Lidija Petrushevska-Tozi ${ }^{2}$, Tanja Petreska Ivanovska ${ }^{2}$ \\ ${ }^{1}$ Replek Farm, Kozle 188, 1000 Skopje, Republic of North Macedonia \\ ${ }^{2}$ Faculty of Pharmacy, Ss. Cyril and Methodius University, Mother Theresa 47, \\ 1000 Skopje, Republic of North Macedonia
}

\section{Introduction}

Ergosterol is a major sterol found as a constituent of the cell wall of plants and hence can be used as a chemical marker of the presence of fungal contamination. Colonization of plants by saprophytic fungi is in increasing problem, thus the analysis of ergosterol as the most common sterol of Ascomyceta and Basidomyceta might be a reliable parameter to assess the intensity of colonization by these fungi (Lohr et al., 2017). Among other phytosterols found in cannabis plant, ergosterol was also identified and hence may be applied as an indicator of fungal contamination of raw material used to manufacture herbal medicines. In this study, two extraction procedures were compared in attempt to develop an adequate HPLC method for analyzing ergosterol in cannabis raw materials which could be applicable in routine practice.

\section{Materials and methods}

\section{Materials}

Ergosterol standard (5,7,22-ergostatrien-3 $\beta$-ol; LRAB7469; purity 99.6\%) was purchased from Sigma Aldrich. Two samples kindly donated from Replek Farm, Skopje were used to test the potential contamination with ergosterol: Cannabis flos, Bedrocan Nira and Cannabis flos, Bedrolite Noi IR.

\section{Sample extraction method}

The first extraction method was based on a saponification to release esterified ergosterol from cytosolic lipid particles providing total ergosterol to be quantified (Rychtera et al., 2010). Briefly, the samples were hydrolyzed with ethanolic $\mathrm{KOH}$ during $3 \mathrm{~h}$ in a water bath and afterwards the samples were vortexed with equal volume of diethyl ether. The dried extract was dissolved in a mixture of methanol:water (95:5) used as a mobile phase for HPLC analysis. The second method was simple direct extraction using hexane according to Shao et al. (2010). Multiple step extraction was performed and hexane phases were pooled and evaporated (Rotavapor, Switzerland). The extract was dissolved in ethanol before HPLC analysis.

\section{HPLC procedure}

Chromatographic system Varian 920-LC, Palo Alto, USA connected to a Discovery HS C 18 column $(5 \mu \mathrm{m}, 125 \times 4.6 \mathrm{~mm})$ heated at $30{ }^{\circ} \mathrm{C}$ and UV detector was used. Both standard and samples $(20 \mu \mathrm{L})$ were eluted by methanol:water (95:5) at a flow rate of $1.0 \mathrm{~mL} / \mathrm{min}$. Ergosterol was detected at

\footnotetext{
* kristina.v0208@gmail.com
} 
$\lambda=254 \mathrm{~nm}$ and quantified by peak area measurement as well as comparison with peak area of standard solutions.

\section{Results and discussion}

Standard solutions within the concentration range of $0.5-100 \mu \mathrm{g} / \mathrm{mL}$ were used to perform a regression study between the observed area and the injected volume of ergosterol. The linearity and repeatability were assessed with the standard solutions which have been injected six folds successively. Recovery was assessed on the samples (ether and hexane extracts) $(n=3)$ spiked with standard solution of ergosterol. Better recovery and separation of the analyte ergosterol was obtained after alkaline hydrolysis of the samples combined with subsequent extraction with ether. Namely, the chromatograms of the samples extracted by this procedure and loaded with ergosterol at a known concentration showed no interfering peak near the retention time of ergosterol. In contrast, direct extraction with hexane and with added known concentration of ergosterol, showed a peak which was not clearly separated from ergosterol.

Chromatographic analysis of the alkalihydrolyzed samples in which prior to extraction was added a standard solution of ergosterol with the lowest concentration $(0.5 \mu \mathrm{g} / \mathrm{mL})$, showed the adequacy of the method for the identification and quantification of ergosterol which concentration in a given sample is not less than $0.5 \mu \mathrm{g} / \mathrm{mL}$. Considering the limit of detection and quantification of ergosterol, the applied method is characterized by significant analytical potential for the qualitative and quantitative determination of low levels of ergosterol in different cannabis raw materials. Ergosterol concentration in grains is highly correlated to the production of fungal toxins (Perkowski et al., 2008). Improper conditions of cultivation or storage of cannabis may also result in ergosterol production. McKernan et al. (2015) and Verweij et al. (2000) have detected significant contamination of cannabis with several toxicogenic fungi from the genera Penicillium and Aspergillus. Hence, the method described in this study may be applicative due to the easy, fast and efficient extraction of ergosterol from tested samples allowed for precision and repeatability of the subsequent HPLC analysis. The method is simple, sensitive and relatively inexpensive and can be adapted for routine use in specialized laboratories which control the quality of cannabis raw materials for the production of herbal medicinal products.

\section{Conclusion}

The use of ergosterol as an analytical parameter for assessment of the potential fungal contamination of raw cannabis can help adequate preventive measures to be developed and on time control strategies to be applied by the manufacturers.

\section{Acknowledgements}

The authors like to thank the pharmaceutical company Replek Farm for providing samples to carry out the experiments.

\section{References}

Lohr, D., Woeck, Ch., Meinken, E., 2017. Use of ergosterol as an indicator for colonization of peatbased growing media by saprophytic fungi. Eur. J. Hortic. Sci. 82, 3-11.

McKernan, K., Spangler, J., Zhang, L., Tadigotla, V., Helbert, Y., Foss, T., Smith, D., 2015. Cannabis microbiome sequencing reveals several mycotoxic fungi native to dispensary grade Cannabis flowers. F1000 Res. 4, 1422.

Perkowski, J., Basiński, T., Wiwart, M., Kostecki, M., Buśko, M., Matysiak, A., 2008. The effect of environmental conditions on ergosterol and trichothecene content of naturally contaminated oat grain. Ann. Agric. Environ. Med. 15, 271-276.

Rychtera, M., Cermak, J., Votruba, J., Nahlik, J., Melzoch, K., Kent, C.A., Estela Escalante, W.D., 2010. Optimization of feeding strategy for the ergosterol production by yeasts Saccharomyces cerevisiae. Rev. Colomb. Biotechnol. 12, 77-93.

Shao, S., Hernandez, M., Kramer, J.K., Rinker, D.L., Tsao, R., 2010. Ergosterol profiles, fatty acid composition, and antioxidant activities of button mushrooms as affected by tissue part and developmental stage. J. Agric. Food Chem. 58, 11616-11625.

Verweij, P.E., Kerremans, J.J., Voss, A., Meis, J.F.G.M., 2000. Fungal contamination of tobacco and marijuana. JAMA 284(22), 2875.

Maced. Pharm. Bull. 66 (Suppl 1) 25 - 26 (2020) 